\title{
Three-year results of a modified photodynamic therapy procedure (Ironing PDT) for age-related macular degeneration patients with large lesions
}

This article was published in the following Dove Press journal:

Clinical Ophthalmology

II March 2016

Number of times this article has been viewed

\author{
Tsuyoshi Otsuji \\ Kenichiro Sho ${ }^{2}$ \\ Akiko Tsumura' \\ Naoko Koike' \\ Tetsuya Nishimura' \\ Kanji Takahashi ${ }^{2}$ \\ 'Department of Ophthalmology, \\ Kansai Medical University, \\ Takii Hospital, ${ }^{2}$ Department of \\ Ophthalmology, Kansai Medical \\ University, Hirakata Hospital, \\ Osaka, Japan
}

Background: To evaluate the effect of photodynamic therapy (PDT) using a modified procedure on exudative age-related macular degeneration having been conventionally difficult to treat.

Methods: The medical records of eight consecutive patients (eight eyes) with age-related macular degeneration treated with modified PDT were reviewed retrospectively. Modified PDT was used for the lesions that could not be covered by conventional use of PDT, either because the lesion was too large or too close to the optic disc. A moving PDT laser spot at constant speed, for 83 seconds, was used to cover the entire lesion, and was named "Ironing PDT." This retrospective study was performed with informed patient consent. It was approved by the Institutional Review Board of Kansai Medical University.

Results: No exudation could be found 36 months after treatment in five eyes (62.5\%). There was no significant difference between the best-corrected visual acuity before PDT (0.95 logMAR) and after PDT (1.09 $\log$ MAR). The $\log$ MAR best-corrected visual acuity was improved in one eye, maintained in five eyes, and deteriorated in two eyes.

Conclusion: Ironing PDT decreased subfoveal fluid and preserved visual acuity in some patients with age-related macular degeneration difficult to treat with conventional therapy.

Keywords: AMD, PCV, PDT, Ironing PDT, modified PDT, large lesions

\section{Introduction}

Intravitreal administration of antivascular endothelial growth factor drugs (anti-VEGF drugs) has become the standard treatment for exudative age-related macular degeneration (AMD). However, there are some patients who do not respond to the drugs at the induction phase (initial nonresponders). Some patients respond to the drugs at the induction phase, but their responses decrease after repeated administrations (tachyphylaxis). We had previously reported that $12.3 \%$ of AMD patients were identified as initial nonresponders and $4.5 \%$ were identified with tachyphylaxis. ${ }^{1}$ Moreover, we had to use the anti-VEGF drugs sparingly for patients who had cerebrovascular or cardiovascular diseases. For all these patients, photodynamic therapy (PDT) is important as a second treatment option. Data from the Treatment of Age-Related Macular Degeneration with Photodynamic Therapy (TAP) study showed that verteporfin therapy of subfoveal choroidal neovascularization (CNV) of AMD patients safely reduced the risk of vision loss. ${ }^{2-5}$ Guidelines for the use of verteporfin in Japan showed that visual acuity was effectively maintained in all lesion types for at least 12 months. ${ }^{6}$ However, it is sometimes impossible to cover a large lesion or a peripapillary lesion. We therefore introduced a modified PDT procedure when the lesion was too large or too close to the optic disc. This procedure was designated "Ironing PDT." In the
Correspondence: Tsuyoshi Otsuji Department of Ophthalmology, Kansai Medical University, Takii Hospital, I0-I5 Fumizono-cho, Moriguchi, Osaka 570-8507, Japan

Tel +8 I 666992 I00 I

Fax +8I 6669928263

Email otsuji@takii.kmu.ac.jp (c) 1 (7) (5) 2016 Otsuji et al. This work is published and licensed by Dove Medical Press Limited. The full terms of this license are available at https://www.dovepress.com/terms.php BY NC and incorporate the Creative Commons Attribution - Non Commercial (unported, v3.0) License (http:///creativecommons.org/licenses/lby-nc/3.0/). By accessing the work you
hereby accept the Terms. Non-commercial uses of the work are permitted without any further permission from Dove Medical Press Limited, provided the work is properly attributed. For permission for commercial use of this work, please see paragraphs 4.2 and 5 of our Terms (https://www.dovepress.com/terms.php). 
following report, the 3-year results of Ironing PDT were retrospectively determined for these AMD patients.

\section{Materials and methods}

We reviewed retrospectively eight eyes of eight patients with AMD who received Ironing PDT from April 2009 to September 2010 at the Kansai Medical University, Takii Hospital (Table 1). We chose PDT because anti-VEGF therapy was either not effective for these patients, or the patients had a history of cerebrovascular infarction or cardiovascular disease. Ironing PDT was used for the lesions that could not be covered by conventional use of PDT, either because the lesion was too large or too close to the optic disc (Figure 1). Patients were followed up for more than 36 months after they received Ironing PDT. This retrospective study was performed with informed patient consent, and was conducted in accordance with the tenets of the Declaration of Helsinki. It was approved by the Institutional Review Board of Kansai Medical University.

Ironing PDT was a modified PDT procedure. The dosages of verteporfin and laser power were set based on the guidelines for PDT in Japan by the Ophthalmic PDT Study Group. ${ }^{6}$ The PDT laser spot moved back and forth at a constant speed, for 83 seconds, to cover the entire lesion. We moved the PDT laser spot to make one back-and-forth motion in 83 seconds as we were checking the time counter (Figure 1).

There were six males and two females in this study, and the mean age of all patients was 73.9 years. There were four eyes with typical AMD and four eyes with polypoidal choroidal vasculopathy (PCV). Four eyes had a large lesion and four eyes had a lesion close to the optic disc. They were not fully treated with anti-VEGF drugs, because one eye was classified as an initial nonresponder and two eyes had tachyphylaxis. There were three eyes of three patients who had a history of cerebrovascular infarction, and one eye of one patient who had a history of cardiovascular disease. One patient did not agree to receive anti-VEGF therapy. Among eyes with typical AMD, one eye had predominantly classic $\mathrm{CNV}$ and three eyes had occult CNV. The greatest mean linear dimension was 7,974 (4,740-11,314) $\mu \mathrm{m}$. We calculated the greatest linear dimension based on the analysis of both fluorescein angiography and indocyanine green angiography. We determined the spot size by using the smaller diameter of the lesion instead of the greatest linear dimension. When indocyanine green angiography-guided PDT reduced the size of the laser spot and could cover the entire lesion, patients underwent indocyanine green angiography-guided PDT instead of Ironing PDT. Ironing PDT was performed using a laser spot, after a $1,000 \mu \mathrm{m}$ margin was added to the measurement.

Patients were seen approximately every 4 weeks. A comprehensive ophthalmic examination, including best-corrected visual acuity (BCVA) and spectral domain optical coherence tomography imaging using the RTVue-100 (Optovue Inc., Fremont, CA, USA), was performed at every visit. BCVA was measured with a Japanese standard decimal visual

Table I Age-related macular degeneration patients treated with Ironing PDT

\begin{tabular}{|c|c|c|c|c|c|c|c|c|}
\hline Case no & $\begin{array}{l}\text { Age } \\
\text { (years) }\end{array}$ & $\begin{array}{l}\text { AMD } \\
\text { type }\end{array}$ & $\begin{array}{l}\text { CNV } \\
\text { lesion }\end{array}$ & $\begin{array}{l}\text { The reason } \\
\text { for choosing } \\
\text { PDT }\end{array}$ & $\begin{array}{l}\text { BCVA before } \\
\text { Ironing PDT }\end{array}$ & $\begin{array}{l}\text { BCVA } 36 \\
\text { months after } \\
\text { Ironing PDT }\end{array}$ & $\begin{array}{l}\text { Additional } \\
\text { treatments in } 36 \\
\text { months follow-up }\end{array}$ & $\begin{array}{l}\text { Macular findings } \\
36 \text { months after } \\
\text { Ironing PDT }\end{array}$ \\
\hline 1 & 75 & PCV & Peripapillary & $\begin{array}{l}\text { Cerebrovascular } \\
\text { infarction }\end{array}$ & 0.15 & 0.1 & Ironing PDT ×3 & Scarring \\
\hline 2 & 83 & PCV & Peripapillary & $\begin{array}{l}\text { Cerebrovascular } \\
\text { infarction }\end{array}$ & 0.08 & 0.05 & None & Scarring \\
\hline 3 & 78 & PCV & Large & $\begin{array}{l}\text { Cerebrovascular } \\
\text { infarction }\end{array}$ & 0.04 & 0.05 & $\begin{array}{l}\text { PPV for vitreous } \\
\text { hemorrhage }\end{array}$ & Scarring \\
\hline 4 & 75 & tAMD & Peripapillary & $\begin{array}{l}\text { Tachyphylaxis } \\
\text { to IVB }\end{array}$ & 0.05 & 0.1 & None & Scarring \\
\hline 5 & 57 & tAMD & Large & Refuse IVR & 0.08 & 0.08 & None & Scarring \\
\hline 6 & 77 & tAMD & Large & $\begin{array}{l}\text { Cardiovascular } \\
\text { disease }\end{array}$ & 0.2 & 0.08 & None & Exudative \\
\hline 7 & 72 & tAMD & Large & $\begin{array}{l}\text { Nonresponder } \\
\text { to IVR }\end{array}$ & 0.6 & 0.15 & $\begin{array}{l}\text { Ironing PDT with } \\
\text { IVR } \times 2\end{array}$ & Scarring \\
\hline 8 & 74 & PCV & Peripapillary & $\begin{array}{l}\text { Tachyphylaxis } \\
\text { to IVR }\end{array}$ & 0.1 & 0.1 & Ironing PDT with IVR & Exudative \\
\hline
\end{tabular}

Notes: There was no significant difference between the mean logMAR BCVA before treatment and the mean logMAR BCVA after treatment $(P=0.809$, paired $t$-test). The logMAR BCVA improved in one eye (I2.5\%), was maintained in five eyes (62.5\%), and deteriorated in two eyes (25.0\%).

Abbreviations: BCVA, best-corrected visual acuity; CNV, choroidal neovascularization; IVB, intravitreous bevacizumab; IVR, intravitreous ranibizumab; logMAR, logarithm of the minimum angle of resolution; PCV, polypoidal choroidal vasculopathy; PDT, photodynamic therapy; PPV, pars plana vitrectomy; tAMD, typical age-related macular degeneration. 

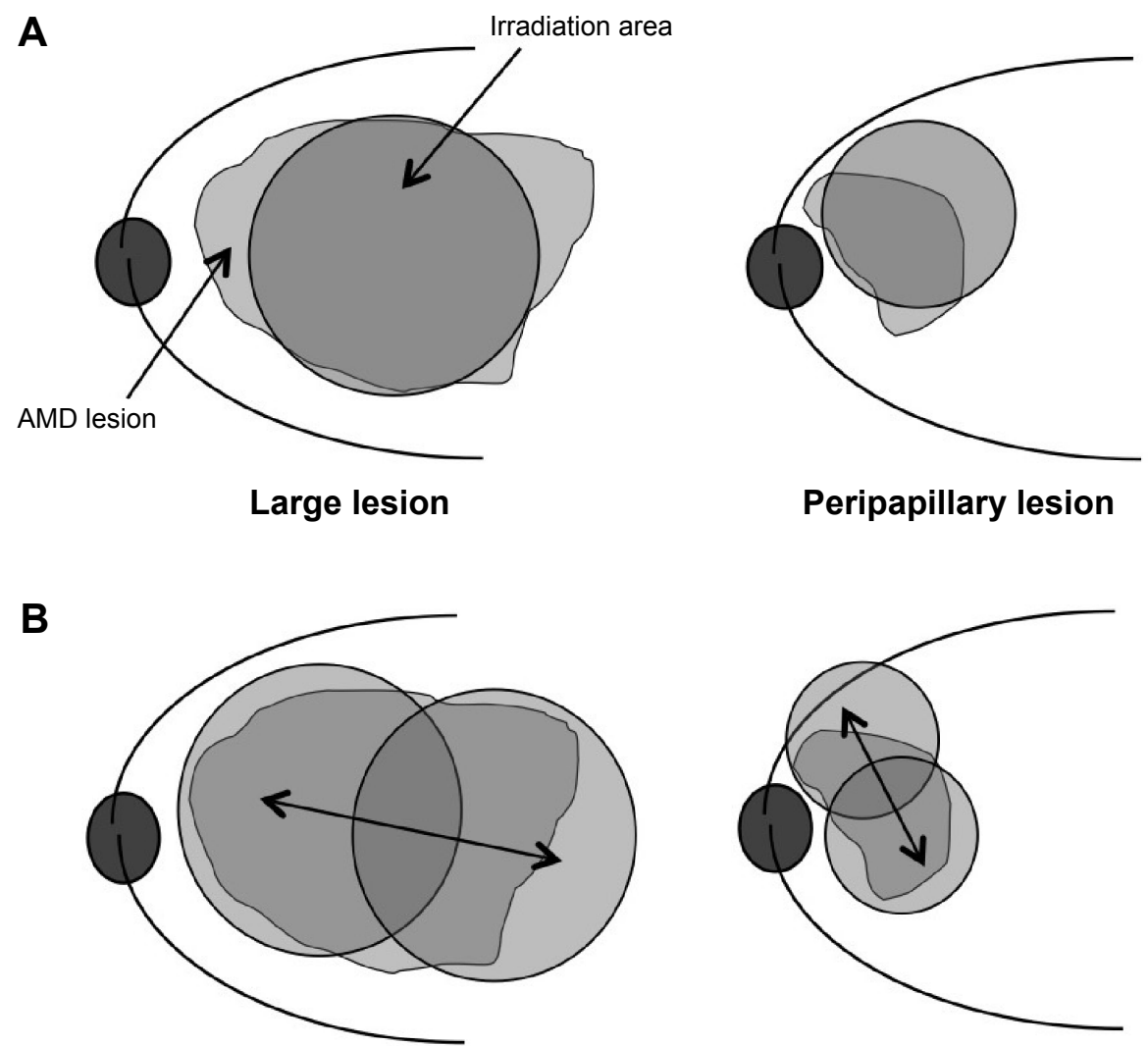

Figure I Schema of PDT.

Notes: (A) The PDT laser spot sometimes cannot cover a large lesion or a peripapillary lesion. (B) Using Ironing PDT, the PDT laser spot is moved at a constant speed, for 83 seconds, to cover the entire lesion. Double-headed arrows show the movement of laser spot.

Abbreviations: AMD, age-related macular degeneration; PDT, photodynamic therapy.

chart, and the logarithm of the minimum angle of resolution (logMAR) scale was used for statistical analysis. A significant change in visual acuity was defined as a difference of 0.3 or more units.

\section{Results}

Figure 2 shows the changes in visual acuity. The mean $\log$ MAR BCVA before treatment was $0.95 \pm 0.37$ and after treatment was $1.09 \pm 0.71$. There was no significant difference between them ( $P=0.809$, paired $t$-test $)$. The logMAR BCVA improved in one eye (12.5\%), was maintained in five eyes $(62.5 \%)$, and deteriorated in two eyes (25.0\%). In five eyes $(62.5 \%)$, no exudation was found and a fibrotic scar developed 36 months after the first Ironing PDT. In 36 months of follow-up, three eyes needed additional PDT. Among them, one eye received three additional Ironing PDT, one eye received two additional treatments (Figures 3-5), and one eye received one additional treatment. The mean number of additional PDT was 1.8 times within 36 months after the first Ironing PDT. Vitreous hemorrhage occurred in one eye with PCV (12.5\%), 23 months after the Ironing PDT.
The patient received vitrectomy, and a fibrotic scar developed at the lesion (Table 1). No complications due to the Ironing PDT, such as unexpected hemorrhage, were found in 36 months follow-up.

\section{Discussion}

PDT has reduced the risk of vision loss for AMD patients with subfoveal CNV. PDT is considered to be effective, especially for PCV. Data from the EVEREST study showed that PDT combined with intravitreal ranibizumab (IVR) or alone was superior to IVR monotherapy in achieving complete regression of polyps in patients with symptomatic PCV. ${ }^{7}$ However, several studies have reported that PDT damages the choriocapillaris layer, and repeated PDT led to persistent nonperfusion of choriocapillaris in most eyes. ${ }^{89}$ When compared with standard-fluence treatment, Michels et $\mathrm{a}^{10}{ }^{10}$ reported that reduced-fluence PDT led to less damage to the choriocapillaris. With Ironing PDT, moving the laser spot makes the irradiation time shorter at each spot. Yamashita et $\mathrm{al}^{11}$ reported the results of a 2-year follow-up study of Japanese PCV patients treated with 


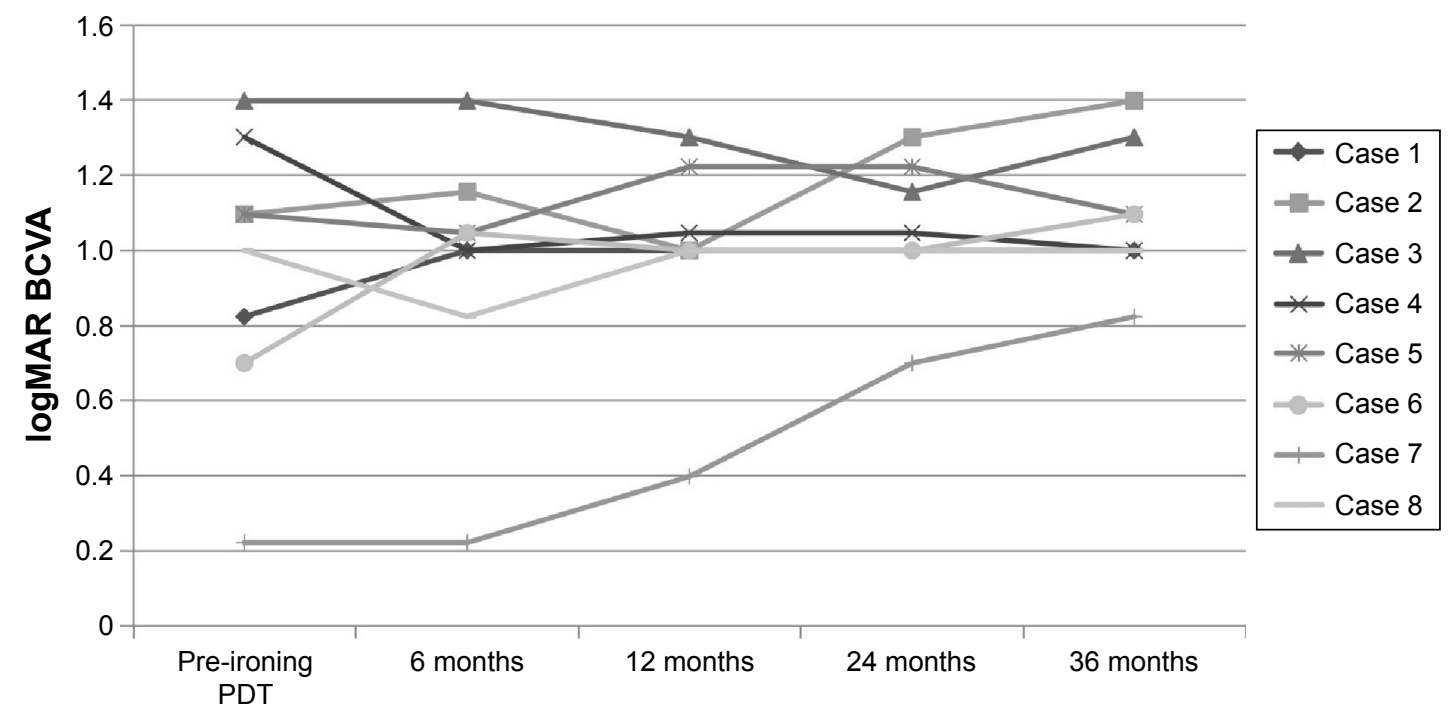

Figure 2 The change in BCVA (evaluated in logMAR).

Note: The mean logMAR BCVA before treatment was 0.95 , and after treatment was 1.09 , with no significant difference.

Abbreviations: BCVA, best-corrected visual acuity; logMAR, logarithm of the minimum angle of resolution; PDT, photodynamic therapy.

reduced-fluence PDT monotherapy. The logMAR BCVA was stable or improved by $\geq 0.3$ in $95 \%$ of the eyes at the 2-year follow-up. In this same report, they reduced the light fluence to $25 \mathrm{~J} / \mathrm{cm}^{2}$, with 83 seconds of irradiation time. Sakurai et al ${ }^{12}$ reported the efficacy of IVR combined with reduced-fluence PDT for PCV. They performed PDT for 42 seconds with a fluence of $50 \mathrm{~J} / \mathrm{cm}^{2}$. To reduce the total energy, they shorten the exposure time to half of the standard time of 83 seconds. They reported that the IVR and reduced-fluence PDT combination led to significant BCVA improvements and required fewer additional IVR treatments for at least 12 months in eyes with PCV.

Rosenblatt et $a{ }^{13}$ reported the efficacy of PDT in the management of symptomatic extrafoveal peripapillary $\mathrm{CNV}^{13}$ using a laser spot that was divided into three 30 seconds minimally overlapping areas that were concentric to the

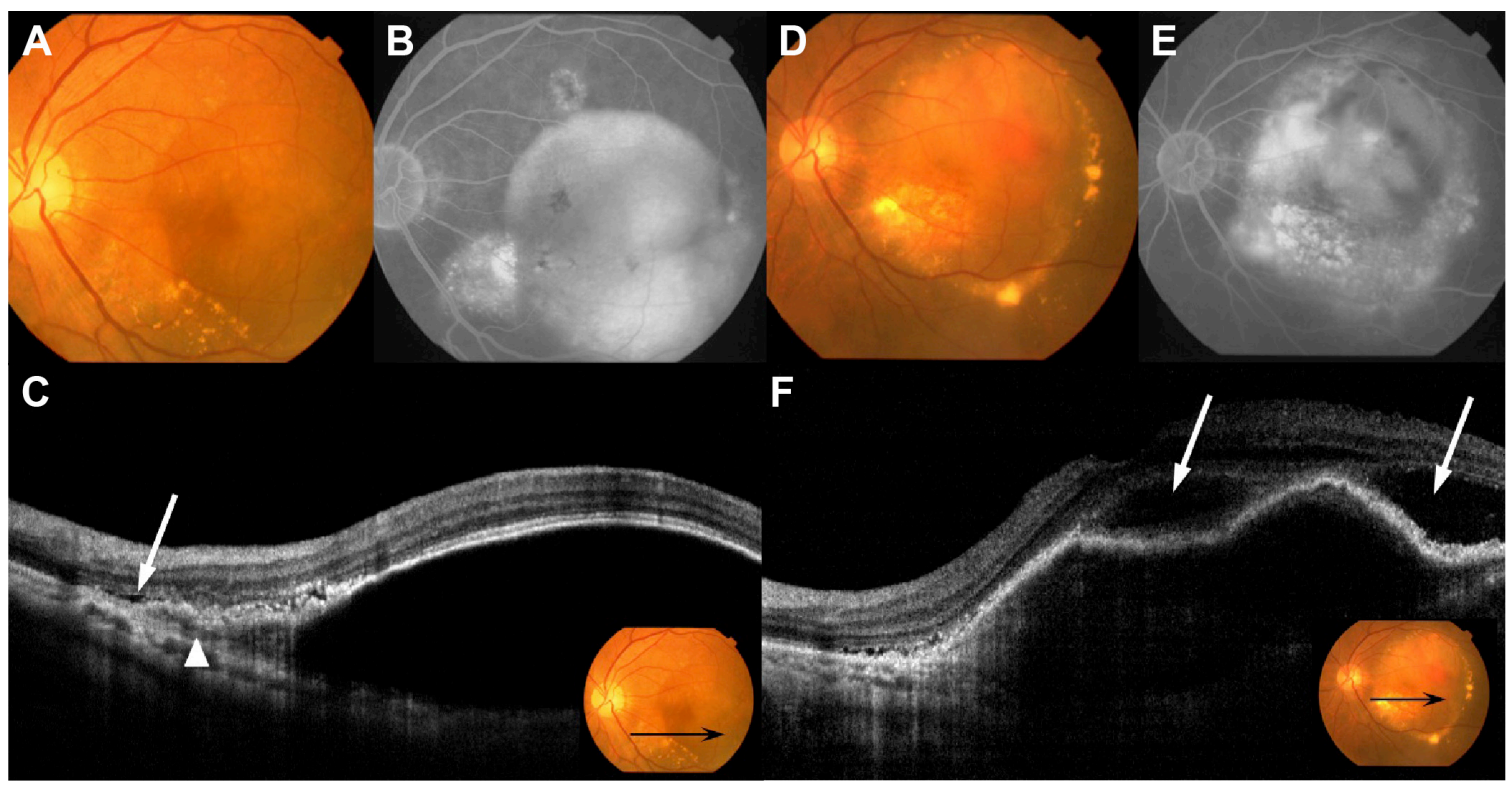

Figure 3 Fundus photography, FA, ICGA, and OCT performed in patient 7.

Notes: (A) Baseline fundus examination shows large serous PED. (B) Late-phase FA shows typical findings of occult CNV and pooling, which demonstrates the presence of serous PED. (C) Baseline OCT shows the presence of type I CNV (arrowhead) and serous PED with SRD (white arrow). Inset shows the position of the scanned line (black arrow) of the OCT. (D) After five treatments of IVR, serous PED and SRD still existed, and CNV moved into the serous PED. (E) Late-phase FA shows strong leakage into the PED, indicative of fibrovascular PED. (F) OCT shows a hyper-reflective lesion under the RPE, with SRD (white arrows). Inset shows the position of the scanned line (black arrow) of the OCT. Abbreviations: CNV, choroidal neovascularization; FA, fluorescein angiography; ICGA, indocyanine green angiography; IVR, intravitreal injections of ranibizumab; OCT, optical coherence tomography; PED, pigment epithelial detachment; RPE, retinal pigment epithelium; SRD, serous retinal detachment. 

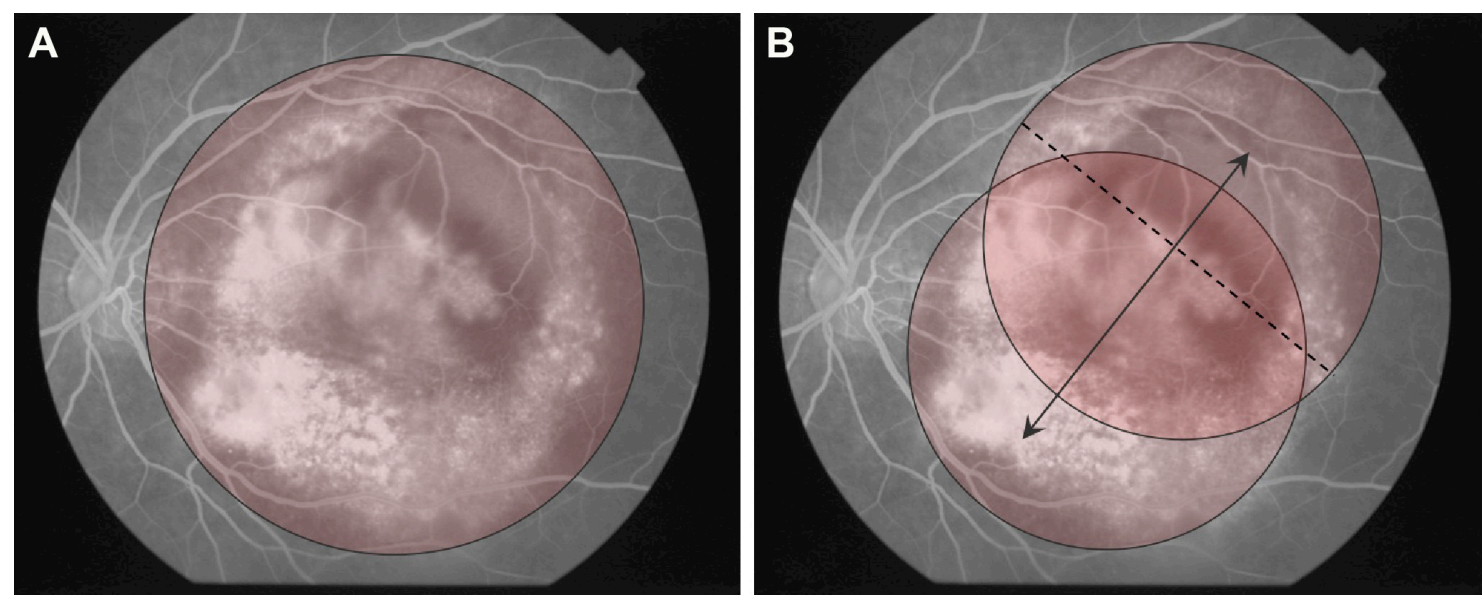

Figure 4 Ironing PDT performed in patient 7.

Notes: (A) Because the mean GLD was $9,980 \mu \mathrm{m}$, conventional PDT could not cover the entire lesion. (B) The laser spot was moved at a constant speed, for 83 seconds, to cover the entire lesion using a 7,200 $\mu \mathrm{m}$ laser spot (dashed line), after a I,000 $\mu \mathrm{m}$ margin was added to the smaller diameter of the lesion. Double-headed arrow shows the movement of laser spot.

Abbreviations: GLD, greatest linear dimension; PDT, photodynamic therapy.

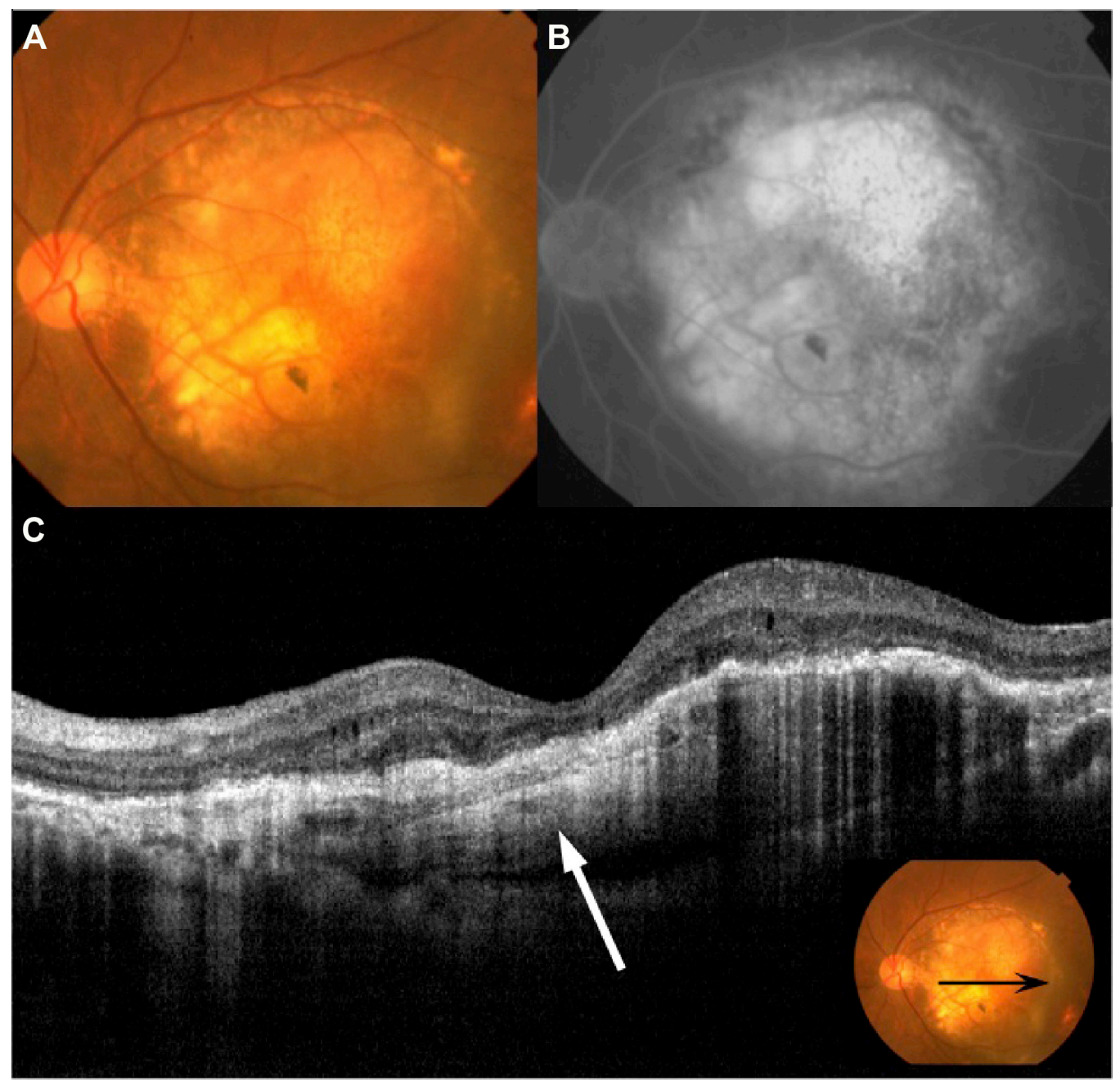

Figure 5 Fundus photography, FA and OCT 36 months after the first Ironing PDT performed in patient 7.

Notes: (A) Fundus examination shows CNV was scarred and exudation was resolved. (B) Late-phase FA shows hyperfluorescence of fibrosis. (C) OCT shows a hyperreflective lesion under the RPE (white arrow), but exudation was not observed. Inset shows the position of the scanned line (black arrow) of the OCT.

Abbreviations: CNV, choroidal neovascularization; FA, fluorescein angiography; OCT, optical coherence tomography; PDT, photodynamic therapy; RPE, retinal pigment epithelium. 
optic nerve. However, using this method, the lesions could be undertreated because lesions still existed that were not covered with the laser spot. Wachtlin et al ${ }^{14}$ described a new "paint-brush technique" for peripapillary and large choroidal hemangiomas. ${ }^{14}$ The use of this technique allowed complete treatment of choroidal hemangiomas with visual control. It involved moving the laser spot at constant speed eccentrically around the lesion's center and over the entire tumor surface. The technique was reported to be a safe and effective modification for the treatment of symptomatic choroidal hemangiomas.

Many studies reported that aflibercept was effective for nonresponders and patients having tachyphylaxis to ranibizumab. However, we often find patients who are nonresponders or who have tachyphylaxis when given aflibercept. These cases are considered to be an indication for PDT, and Ironing PDT might be a good candidate for treating cases with large lesions or lesions close to the optic disc.

\section{Conclusion}

In conclusion, moving the laser spot makes the irradiation time shorter at each area, resulting in suppression of the exudation without excessive irradiation. Ironing PDT resolved the fluid accumulation successfully in $62.5 \%$ of the patients, but did not prevent deterioration of BCVA in some patients. There are several limitations in this study. Further research with a larger number of patients is needed to improve the technique of Ironing PDT and confirm the effect for long periods of time. Our data suggest that Ironing PDT may be a treatment option in patients with AMD difficult to treat with anti-VEGF agents or conventional PDT.

\section{Acknowledgments}

The manuscript was presented at the World Ophthalmology Congress of the International Council of Ophthalmology in Tokyo as an oral free paper presentation with interim findings on April 4, 2014.

\section{Disclosure}

The authors report no conflicts of interest in this work.

\section{References}

1. Otsuji T, Nagai Y, Sho K, et al. Initial non-responders to ranibizumab in the treatment of age-related macular degeneration (AMD). Clin Ophthalmol. 2013;7:1487-1490.

2. Treatment of Age-Related Macular Degeneration with Photodynamic Therapy (TAP) study group. Photodynamic therapy of subfoveal choroidal neovascularization in age-related macular degeneration with verteporfin: one-year results of 2 randomized clinical trials - TAP report. Arch Ophthalmol. 1999;117(10):1329-1345.

3. Treatment of Age-Related Macular Degeneration with Photodynamic Therapy (TAP) study group. Photodynamic therapy of subfoveal choroidal neovascularization in age-related macular degeneration with verteporfin: two-year results of 2 randomized clinical trials-tap report 2. Arch Ophthalmol. 2001;119(2):198-207.

4. Treatment of Age-Related Macular Degeneration with Photodynamic Therapy (TAP) study group. Verteporfin therapy of subfoveal choroidal neovascularization in patients with age-related macular degeneration: additional information regarding baseline lesion composition's impact on vision outcomes - TAP report No 3. Arch Ophthalmol. 2002;120(11):1443-1454.

5. Treatment of Age-Related Macular Degeneration with Photodynamic Therapy (TAP) study group. Verteporfin therapy for subfoveal choroidal neovascularization in age-related macular degeneration: three-year results of an open-label extension of 2 randomized clinical trials - TAP report No.5. Arch Ophthalmol. 2002;120(10):1307-1314.

6. Tano Y; Ophthalmic PDT Study Group. Guidelines for PDT in Japan. Ophthalmology. 2008;115(3):585-585.e6.

7. Koh A, Lee WK, Chen LJ, et al. EVEREST study: efficacy and safety of verteporfin photodynamic therapy in combination with ranibizumab or alone versus ranibizumab monotherapy in patients with symptomatic macular polypoidal choroidal vasculopathy. Retina. 2012;32(8):1453-1464.

8. Schmidt-Erfurth U, Michels S, Barbazetto I, Laqua H. Photodynamic effects on choroidal neovascularization and physiological choroid. Invest Ophthalmol Vis Sci. 2002;43(3):830-841.

9. Schmidt-Erfurth U, Laqua H, Schlötzer-Schrehard U, Viestenz A, Naumann GO. Histopathological changes following photodynamic therapy in human eyes. Arch Ophthalmol. 2002;120(6):835-844.

10. Michels S, Hansmann F, Geitzenauer W, Schmidt-Erfurth U. Influence of treatment parameters on selectivity of verteporfin therapy. Invest Ophthalmol Vis Sci. 2006;47(1):371-376.

11. Yamashita A, Shiraga F, Shiragami C, Shirakata Y, Fujiwara A. Twoyear results of reduced-fluence photodynamic therapy for polypoidal choroidal vasculopathy. Am J Ophthalmol. 2013;155(1):96-102.e1.

12. Sakurai M, Baba T, Kitahashi M, et al. One-year results of intravitreal ranibizumab combined with reduced-fluence photodynamic therapy for polypoidal choroidal vasculopathy. Clin Ophthalmol. 2014;8:235-241.

13. Rosenblatt BJ, Shah GK, Blinder K. Photodynamic therapy with verteporfin for peripapillary choroidal neovascularization. Retina. 2005;25(1):33-37.

14. Wachtlin J, Spyridaki M, Stroux A, Bechrakis NE, Foerster M. [Therapy for peripapillary located and large choroidal haemangioma with PDT 'paint-brush technique']. Klin Monbl Augenheilkd. 2009; 226(11):933-938. German.
Clinical Ophthalmology

\section{Publish your work in this journal}

Clinical Ophthalmology is an international, peer-reviewed journal covering all subspecialties within ophthalmology. Key topics include: Optometry; Visual science; Pharmacology and drug therapy in eye diseases; Basic Sciences; Primary and Secondary eye care; Patient Safety and Quality of Care Improvements. This journal is indexed on Submit your manuscript here: http://www.dovepress.com/clinical-ophthalmology-journal

\section{Dovepress}

PubMed Central and CAS, and is the official journal of The Society of Clinical Ophthalmology (SCO). The manuscript management system is completely online and includes a very quick and fair peer-review system, which is all easy to use. Visit http://www.dovepress.com/ testimonials.php to read real quotes from published authors. 